\title{
Outcome of antenatal hydronephrosis in northeastern Thailand
}

\author{
Pongsatorn Paopongsawan ${ }^{\mathrm{a}}$, Suwannee Wisanuyotin ${ }^{\mathrm{a}}$, Ratana Komwilaisak ${ }^{\mathrm{b}}$, Junya Jirapradittha ${ }^{\mathrm{a}}$, Apichat \\ Jiravuttipong ${ }^{\mathrm{a}}$, Pakaphan Kiatchoosakun ${ }^{\mathrm{a}}$ \\ ${ }^{a}$ Department of Pediatrics, Faculty of Medicine, Khon Kaen University, ${ }^{b}$ Department of Obstetrics \\ and Gynecology, Faculty of Medicine, Khon Kaen University, Khon Kaen 40002, Thailand
}

\begin{abstract}
Background: Antenatal hydronephrosis (ANH) is a condition characterized by fetal renal pelvic dilatation during pregnancy. It is detected in 1\%-5\% of all pregnancies. Most cases of ANH are physiological in nature, but some are pathological and can cause morbidity.

Objective: To determine: (a) the causes of ANH; (b) the factors associated with complications; and, (c) the factors associated with surgical intervention.

Methods: We reviewed the medical records of infants diagnosed with ANH; defined by a renal pelvic anteroposterior diameter $\geq 5 \mathrm{~mm}$ (based on antenatal ultrasonography) and being followed-up at Srinagarind Hospital.

Results: Forty-six infants (32 boys and 14 girls) with ANH were identified. Over half (57\%) were born in our hospital (in-hospital) with the condition. The two most common causes of ANH were ureteropelvic junction obstruction (32\%) and transient hydronephrosis (22\%). Of the 63 abnormal kidneys, 52\% needed surgical intervention. Twenty-two patients (48\%) had urinary tract infections and most had more than 1 episode. None of the 46 patients had end-stage renal disease, but one died because of lung hypoplasia during the neonatal period. The severity of ANH and time of first postnatal ultrasonography were related to medical complications, while bilateral ANH and more severe ANH were associated with the need for surgical intervention. A milder degree of ANH and postnatal ultrasound findings were significantly associated with transient hydronephrosis. Conclusion: Most cases of ANH were pathological and half required surgical intervention. Severe ANH and delayed investigation were associated with poor outcomes.
\end{abstract}

Keywords: Antenatal hydronephrosis, cause, complication, outcome, surgery

Antenatal hydronephrosis (ANH) is characterized by abnormally enlarged kidney(s), which can be detected by antenatal ultrasonography (AUS) between 12 and 40 weeks of gestation [1]. The incidence of ANH is $1 \%-5 \%$ of all pregnancies [1-4]. Most cases of ANH are transient hydronephrosis (64\%) [4], which usually resolves after postnatal follow-up ultrasound [4-8]. However, some cases are pathological—mostly as a result of ureteropelvic junction (UPJ) obstruction (54.3\%), vesicoureteric reflux (VUR) (8.5\%), and posterior urethral valve (PUV) (5.3\%) [4] —and can deteriorate and may require surgical treatment. Patients with $\mathrm{ANH}$ also have a higher risk for urinary tract infection (UTI)

Correspondence to: Suwannee Wisanuyotin, Department of Pediatrics, Faculty of Medicine, Khon Kaen University, Khon Kaen 40002, Thailand. E-mail: drsuwannee@yahoo.com than the normal population $(49 \%-53 \%)[9,10]$. Prospective studies demonstrated that a more severe degree of ANH and bilateral ANH are associated with a higher risk for UTI and the need for surgical intervention [11]. The objectives of the current study were to determine (a) the causes of ANH, (b) the factors associated with the need for surgical intervention, and (c) the factors associated with complications in patients with ANH.

\section{Materials and methods}

We reviewed the medical records of infants diagnosed with ANH by AUS and followed-up postnatally at Srinagarind Hospital, a supratertiary university hospital in Northeastern Thailand between June 1, 2003 and May 31, 2013. The patients underwent postnatal ultrasonography (PUS) and the severity of ANH was defined by anteroposterior renal pelvic diameter (APD) in the second or third trimester 
of pregnancy (namely, $<5 \mathrm{~mm}=$ normal; $5-9.9 \mathrm{~mm}=$ mild; $10-14.9 \mathrm{~mm}=$ moderate; $\geq 15 \mathrm{~mm}=$ severe) [12-14]. The definitions for PUS were based on the Society for Fetal Urology classification adapted for neonates and infants [15]. We excluded from the study any patients with incomplete medical records or an incomplete antenatal history. The study protocol was reviewed then approved by the institutional review board and the Human Research Ethics Committee of Khon Kaen University, Thailand.

\section{Statistical analyses}

SPSS version 17.0 (SSPS Inc, Chicago, IL, USA) was used for all statistical analyses. Means, medians, standard deviations and interquartile ranges were calculated for the descriptive data. Student $t$ tests and Mann-Whitney $U$ tests were used to compare means and a $\chi^{2}$ test used for correlation analysis. $P<0.05$ was considered statistically significant.

\section{Results \\ Demographic data}

Forty-six patients were identified (32 boys (70\%)). The mean gestational age (GA) at birth was $38.1 \pm$ 1.5 weeks and the mean birth weight was 3,219 \pm $578 \mathrm{~g}$. Twenty-six cases (56\%) were born in-hospital and 20 (44\%) were born and diagnosed at other hospitals (referred). The mean GA at first AUS was $29.0 \pm 5.3$ weeks and the median age at first PUS was 22 (128) days. Further subgroup analysis revealed that the median age at first PUS of patients born inhospital vs. referred was 15 (16) vs. 142 (330) days (Table 1).

\section{Ultrasonographic results}

Antenatal ultrasonographic results

Sixty-three abnormal kidneys were identified in the 46 patients. Twenty-eight patients (61\%) had unilateral hydronephrosis, 17 (37\%) had bilateral hydronephrosis and 1 (2\%) had a single kidney with hydronephrosis. A 22 (35\%), 16 (25\%) and 25 (40\%) kidneys had mild, moderate, and severe ANH, respectively.

\section{Postnatal ultrasonographic results}

Based on the PUS findings, of the 63 abnormal kidneys, 7 (11\%) improved to normal, while a respective 13 (21\%), 18 (29\%) and 25 (40\%) presented mild, moderate, or severe hydronephrosis. A comparison of the AUS and PUS findings revealed that 39 kidneys (62\%) had no changes, while 15 (24\%) improved and 9 (14\%) worsened.

Most patients underwent further investigations including: voiding cystourethrography (VCUG) in 28 cases, renal scan in 19, cystoscopy in 14, intravenous pyelography (IVP) in 12, and computerized tomography/magnetic resonance imaging (CT/MRI) in 6. Fourteen kidneys (22\%) presented transient hydronephrosis while 12 (19\%) had persistent hydronephrosis without any identified cause. Of the remaining kidneys, the most common cause of ANH was UPJ obstruction (32\%) (Table 2).

\section{Surgical requirement}

Of the 46 patients, 24 (52\%) - accounting for 33 of the 63 abnormal kidneys (52\%)-underwent surgical treatment. Among the patients undergoing surgery, 17 (37\%) were boys and 7 (15\%) were girls. Thirteen patients (29\%) had bilateral ANH while 11 (24\%) had unilateral ANH. The majority of patients who underwent surgical correction were referred (33\%) and underwent their first PUS after the first 30 days of life (30\%). Most of the kidneys needing surgical intervention presented severe ANH (29\%).

A higher rate of surgical requirement was significantly associated with bilateral ANH, severe ANH and/or being referred while sex and age of first PUS were not (Table 3 ).

Table 1. Demographic data

\begin{tabular}{|c|c|c|c|c|}
\hline Data & Total & In-hospital birth & Referred & $\boldsymbol{P}$ \\
\hline Place of birth & 46 & $26(56 \%)$ & $20(44 \%)$ & 0.38 \\
\hline \multicolumn{5}{|l|}{ Sex } \\
\hline Male & $32(70 \%)$ & $19(41 \%)$ & $13(28 \%)$ & 0.29 \\
\hline Female & $14(30 \%)$ & $7(15 \%)$ & $7(15 \%)$ & 1.00 \\
\hline Mean GA at birth (weeks) & $38.1 \pm 1.5$ & $37.81 \pm 1.6$ & $38.36(1.4)$ & 0.24 \\
\hline Mean birth weight (g) & $3,219 \pm 578$ & $3,120 \pm 536$ & $3,348(619)$ & 0.19 \\
\hline Mean GA at $1^{\text {st }}$ AUS (weeks) & $29.0 \pm 5.3$ & $28.3 \pm 5.6$ & $29.8(5.0)$ & 0.33 \\
\hline Median age at $1^{\text {st }}$ PUS (days) & $22 \pm 128$ & $15 \pm 16$ & $142(330)$ & $<0.001^{*}$ \\
\hline
\end{tabular}

$* P<0.05$ 
Table 2. Causes of antenatal hydronephrosis

\begin{tabular}{lc}
\hline Causes & Number of kidneys (\%) \\
\hline Transient hydronephrosis & $14(22 \%)$ \\
UPJ obstruction & $20(32 \%)$ \\
Persistent hydronephrosis & $12(19 \%)$ \\
Ureteric obstruction & $6(10 \%)$ \\
VUR & $5(8 \%)$ \\
Duplicated collecting system & $4(6 \%)$ \\
PUV & $2(3 \%)$ \\
\hline
\end{tabular}

Table 3. Factors associated with surgical requirement

\begin{tabular}{|c|c|c|c|}
\hline \multirow[t]{2}{*}{ Factors } & \multicolumn{2}{|c|}{ Surger } & \multirow[t]{2}{*}{$\boldsymbol{P}$} \\
\hline & Yes & No & \\
\hline Surgery (n = 63 kidneys) & $33(52 \%)$ & $30(48 \%)$ & \\
\hline $\operatorname{Sex}(n=46)$ & & & 0.85 \\
\hline Male & $17(37 \%)$ & $15(33 \%)$ & \\
\hline Female & $7(15 \%)$ & $7(15 \%)$ & \\
\hline Laterality $(n=45))^{\dagger}$ & & & $0.022 *$ \\
\hline Unilateral & $11(24 \%)$ & $17(38 \%)$ & \\
\hline Bilateral & $13(29 \%)$ & $4(9 \%)$ & \\
\hline Severity of ANH ( $\mathrm{A}=63$ kidneys) & & & $0.009 *$ \\
\hline Mild & $6(10 \%)$ & $16(25 \%)$ & \\
\hline Moderate & $9(14 \%)$ & $7(11 \%)$ & \\
\hline Severe & $18(29 \%)$ & $7(11 \%)$ & \\
\hline Place of birth $(n=46)$ & & & $0.007 *$ \\
\hline In-hospital birth & $9(20 \%)$ & $17(37 \%)$ & \\
\hline Referred & $15(33 \%)$ & $5(11 \%)$ & \\
\hline Age of $1^{\text {st }}$ PUS $(n=46)$ & & & 0.07 \\
\hline $1-30$ days & $10(22 \%)$ & $15(33 \%)$ & \\
\hline$>30$ days & $14(30 \%)$ & $7(15 \%)$ & \\
\hline
\end{tabular}

${ }^{*} P<0.05,{ }^{\dagger} \mathrm{n}=45$ because of exclusion of one patient who had single kidney

\section{Complications}

Complications included urinary tract infections (UTIs), chronic kidney disease (CKD)/end-stage renal disease (ESRD), and death. Of the 46 patients, 23 (50\%) had complications. UTIs were diagnosed in 22 patients (48\%), and most of them (17 patients; $37 \%$ of the total) had recurrent UTIs. None of the patients had progressed to CKD/ESRD during the mean follow-up time of $23.2 \pm 18.3$ months but 1 (2\%) died because of pulmonary hypoplasia during the first week of life.

Among the patients with complications (14, 30\% boys and 9, 20\% girls), 10 (22\%) had bilateral ANH while 13 (29\%) had unilateral ANH. The majority of patients with complications were referred (30\%), 24\% had moderate ANH and 24\% had severe ANH. About one-half of patients with complications underwent their first PUS after the first 30 days of life (24\%).

Data analysis indicated that (a) the severity of AUS, (b) being a referred patient, and (c) age of first PUS after the first 30 days of life were significantly associated with a higher rate of complications, whereas sex and laterality of ANH were not (Table 4).

\section{Transient hydronephrosis}

Transient hydronephrosis was found in 14 of 63 abnormal kidneys (22\%) in 11 of the 46 patients (24\%). The clinical characteristics of those patients are presented in Table 5. A milder degree of AUS and PUS findings was significantly associated with transient hydronephrosis, while sex and laterality of ANH showed no significant association. 
Table 4. Factors associated with complications

\begin{tabular}{|c|c|c|c|}
\hline \multirow[t]{2}{*}{ Factors } & \multicolumn{2}{|c|}{ Complications } & \multirow[t]{2}{*}{$P$} \\
\hline & $\overline{\text { Yes }}$ & No & \\
\hline $\operatorname{Sex}(n=46)$ & $23(50 \%)$ & $23(50 \%)$ & 0.2 \\
\hline Male & $14(30 \%)$ & $18(39 \%)$ & \\
\hline Female & $9(20 \%)$ & $5(11 \%)$ & \\
\hline Laterality $(n=45)^{\dagger}$ & & & 0.6 \\
\hline Unilateral & $13(29 \%)$ & $15(33 \%)$ & \\
\hline Bilateral & $10(22 \%)$ & $7(16 \%)$ & \\
\hline Severity of ANH $(n=46)^{\ddagger}$ & & & $<0.001^{*}$ \\
\hline Mild & $1(2 \%)$ & $13(28 \%)$ & \\
\hline Moderate & $11(24 \%)$ & $2(4 \%)$ & \\
\hline Severe & $11(24 \%)$ & $8(17 \%)$ & \\
\hline Place of birth $(n=46)$ & & & $0.017^{*}$ \\
\hline In-hospital birth & $9(20 \%)$ & $17(37 \%)$ & \\
\hline Referred & $14(30 \%)$ & $6(13 \%)$ & \\
\hline Age of $1^{\text {st }}$ PUS $(n=46)$ & & & $0.028 *$ \\
\hline $1-30$ days & $12(26 \%)$ & $19(41 \%)$ & \\
\hline$>30$ days & $11(24 \%)$ & $4(9 \%)$ & \\
\hline
\end{tabular}

${ }^{*} P<0.05,{ }^{\dagger} \mathrm{n}=45$ because of exclusion of one patient who had single kidney, ${ }^{\star}$ based on the most severe finding from AUS in each patient

Table 5. Factors associated with transient hydronephrosis

\begin{tabular}{|c|c|c|c|}
\hline \multirow[t]{2}{*}{ Factors } & \multicolumn{2}{|c|}{ Transient hydronephrosis } & \multirow[t]{2}{*}{$\boldsymbol{P}$} \\
\hline & Yes & No & \\
\hline $\operatorname{Sex}(n=46)$ & & & 0.79 \\
\hline Male & $8(17 \%)$ & $24(52 \%)$ & \\
\hline Female & $3(7 \%)$ & $11(24 \%)$ & \\
\hline Laterality $(n=45)^{\dagger}$ & & & 0.31 \\
\hline Unilateral & $8(18 \%)$ & $20(44 \%)$ & \\
\hline Bilateral & $3(7 \%)$ & $15(33 \%)$ & \\
\hline Severity of ANH $(n=46)^{\ddagger}$ & & & $<0.001 *$ \\
\hline Mild & $9(20 \%)$ & $5(11 \%)$ & \\
\hline Moderate & $2(4 \%)$ & $11(24 \%)$ & \\
\hline Severe & $0(0 \%)$ & $19(41 \%)$ & \\
\hline $\mathbf{1}^{\text {st }}$ PUS findings $(n=46)^{\ddagger}$ & & & $<0.001^{*}$ \\
\hline Normal & $2(4 \%)$ & $0(0 \%)$ & \\
\hline Mild & $7(15 \%)$ & $3(7 \%)$ & \\
\hline Moderate & $2(4 \%)$ & $14(30 \%)$ & \\
\hline Severe & $0(0 \%)$ & $18(39 \%)$ & \\
\hline
\end{tabular}

$* P<0.05,{ }^{\dagger} \mathrm{n}=45$ because of exclusion of one patient who had single kidney, ${ }^{\ddagger}$ based on the most severe finding from AUS or PUS in each patient

\section{Discussion}

Lee et al. [4] reported that most patients (64\%) with ANH had transient hydronephrosis. By contrast, we found that only $24 \%$ of the patients had transient hydronephrosis. The lower prevalence in our study may be because of the retrospective study design and/ or our tertiary care, referral setting. Patients in our hospital tended to have more complicated cases than those in the general hospital population. The three most commonly identified causes of ANH as in previous studies were: UPJ obstruction (32\%), ureteric obstruction (10\%), and VUR (8\%) [4]. 
In the current study, more than half of the abnormal kidneys (52\%) required surgical treatment. Bilateral hydronephrosis was significantly associated with a requirement for surgical intervention, as reported by Babu et al. [11]. As noted by others $[4,10,11,16]$, the other strongly associated variable was a greater degree of severity of ANH. Interestingly, referred patients underwent surgical treatment significantly more often than those born in-hospital. This might be because of later presentation leading to later investigations (median age at first PUS was $142 \pm 330$ days vs. $15 \pm 16$ days, respectively). Therefore, patients with ANH should be referred for further investigation and treatment as soon as possible after birth.

UTI was the most common complication of ANH patients; with $48 \%$ of patients experiencing one or more episodes of UTI. Fortunately, none of the patients had progressed to CKD/ESRD, as in similar previous studies [4-11]. However, one of our patients died because of pulmonary hypoplasia and its potential association with hydronephrosis was unclear. Factors associated with complications were (a) having a greater severity of ANH based on AUS findings, (b) being a referred patient, and (c) having delayed PUS (>30 days after birth). The last two variables could be explained by delayed physician visits by those born outside our institution and referred, resulting in delayed investigations and antibiotic prophylaxis.

In our study, we focused on patients with transient hydronephrosis comprising $24 \%$ of all cases. This condition - which normally requires no further invasive investigation or treatment-is associated with a milder degree of ANH from AUS findings as in previous studies [4-11]. Additionally, the milder the first PUS is, the more likely the association with transient hydronephrosis. Patients with a mild degree of hydronephrosis - based on both the AUS and PUS findings - should, in our opinion, be followed-up with ultrasonography. However, there is no evidential consensus, and therefore invasive investigations in this group of patients can be postponed.

\section{Conclusion}

In the current study, most cases of ANH were pathological and half of them-particularly those with severe and bilateral ANH-required surgical treatment. The greater the severity of ANH, the more likely the association with complications if postnatal investigations are delayed. The milder the degree of
AUS and PUS findings, the more likely the association with transient hydronephrosis, which should not be over-investigated.

Generalizability of this study is limited because of the small sample size and its retrospective nature. Further prospective study including a costeffectiveness analysis should be conducted to clarify whether or not all pregnant women should undergo AUS for early detection of ANH.

\section{Acknowledgements}

The authors thank the Department of Pediatrics and the Faculty of Medicine for support and Mr. Bryan Roderick Hamman for assistance with the Englishlanguage presentation.

The authors have no competing interests.

\section{References}

1. Lee RS, Diamond DA. Perinatal urology. In: Avner ED, Harmon WE, Niaudet P, Yoshikawa N, editors. Pediatric Nephrology 6th ed. Berlin Heidelberg: Springer-Verlag; 2009. p. 95-106.

2. Ek S, Lidefeldt KJ, Varricio L. Fetal hydronephrosis; prevalence, natural history and postnatal consequences in an unselected population. Acta Obstet Gynecol. 2007; 86:1463-6.

3. Garne E, Loane M. Congenital hydronephrosis: prenatal diagnosis and epidemiology in Europe. J Pediatr Urol. 2009; 5:47-52.

4. Lee RS, Cendron M, Kinnamon DD, Nguyen HT. Antenatal hydronephrosis as a predictor of postnatal outcome: a meta-analysis. Pediatrics. 2006; 118:586-93.

5. Coelho GM, Bouzada MC, Pereira AK, Figueiredo BF, Leite MR, Oliveira DS, et al. Outcome of isolated antenatal hydronephrosis: a prospective cohort study. Pediatr Nephrol. 2007; 22:1727-34.

6. Shamshirsaz AA, Ravangard SF, Egan JF, Prabulos AM, Shamshirsaz AA, Ferrer FA, et al. Fetal hydronephrosis as a predictor of neonatal urologic outcomes. J Ultrasound Med. 2012; 31:947-54.

7. Gokaslan F, Yalcynkaya F, Fitoz S, Ozcakar ZB. Evaluation and outcome of antenatal hydronephrosis: a prospective study. Turkey J Pediatr Urol. 2012; 34: 718-21.

8. Longpre M, Nguan A, MacNeily AE, Afshar K. Prediction of the outcome of antenatally diagnosed hydronephrosis: a multivariable analysis. J Pediatr Urol. 2012; 8:135-9.

9. Moorthy I, Joshi N, Cook JV, Warren M. Antenatal hydronephrosis: negative predictive value of normal 
postnatal ultrasound-a 5-year study. Clin Radiol. 2003; 58:964-70.

10. Ahmadzadeh A, Tahmasebi M, Gharibvand MM. Causes and outcome of prenatally diagnosed hydronephrosis. Saudi J Kidney Dis Transpl. 2009; 20:246-50.

11. Babu R, Sai V. Postnatal outcome of fetal hydronephrosis: implications for prenatal counselling. Indian J Urol. 2010; 26:60-2.

12. Chitty LS, Altman DG. Charts of fetal size: kidney and renal pelvis measurements. Prenat Diagn. 2003; 23:891-7.

13. Scott JE, Wright B, Wilson G, Pearson IA, Matthews JN, Rose PG. Measuring the fetal kidney with ultrasonography. Br J Urol. 1995; 76:769-74.

14. Odibo AO, Marchiano D, Quinones JN, Riesch D, Egan JF, Macones GA. Mild pyelectasis: evaluating the relationship between gestational age and renal pelvic anterior-posterior diameter. Prenat Diagn. 2003; 23:824-7.

15. Fernbach SK, Maizels M, Conway JJ. Ultrasound grading of hydronephrosis: introduction to the system used by the Society for Fetal Urology. Pediatr Radiol. 1993; 23:478-80.

16. Tabel Y, Haskologlu ZS, Karakas HM, YakinciC. Ultrasonographic screening of newborns for congenital anomalies of the kidney and the urinary tracts. J Pediatr Urol. 2010; 7:161-7. 